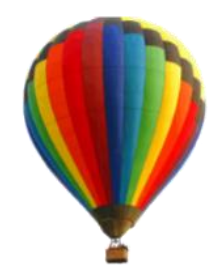

\title{
MELHORIA DE EFICIÊNCIA PRODUTIVA DE UMA LINHA DE PRODUÇÃO: UM ESTUDO DE CASO EM UMA INDÚSTRIA DE PRODUTOS MÉDICOS
}

\section{IMPROVING THE PRODUCTIVE EFFICIENCY OF A PRODUCTION LINE: A CASE STUDY IN A MEDICAL PRODUCTS INDUSTRY}

\section{Larissa Amorin $^{1}$, Thales Volpe Rodrigues ${ }^{2 *}$, \& José Ferreira da Silva Junior ${ }^{3}$}

${ }^{1}$ Faculdade Calafiori. ${ }^{2}$ Universidade Tecnológica Federal do Paraná - UTFPR. ${ }^{3}$ Universidade do estado de Minas Gerais, UEMG. ${ }^{1}$ amorinlarissa86@gmail.com ${ }^{2 *}$ thales.volpe@ hotmail.com ${ }^{3}$ jose.junior@uemg.br

\section{ARTIGO INFO.}

Recebido em: 05.11.2020

Aprovado em: 24.11.2020

Disponibilizado em: $\mathbf{2 5 . 1 1 . 2 0 2 0}$

\section{PalaVRas-ChaVe:}

Eficiência; Produtividade; Layout; Melhoria do

Processo; Arranjos Físicos.

\section{KEYWORDS:}

Efficiency; Productivity; Layout; Process Improvement; Physical Arrangements.

*Autor Correspondente: Rodrigues, T. V.

\section{RESUMO}

A competitividade nos diversos segmentos industriais tem estimulado as organizações a desenvolverem formas de tornar suas operações e processos produtivos cada vez mais eficientes e com maior produtividade. Com isso as empresas buscam características que permitam ter bons resultados em relação à concorrência. Assim, este estudo apresenta conceitos acerca da aplicação de ferramentas, adequação de layout e técnicas para resolução de problemas, melhorando a eficiência produtiva em uma linha de produção, garantindo o aumento da qualidade e produção pelo índice de produtividade e redução de desperdícios, em uma indústria de produtos médicos. O método para a aplicação das ferramentas de melhoria de processo foi dividido em etapas, iniciando com definição de uma estrutura conceitual teórica, seguido pelo planejamento de caso, teste piloto, coleta de dados, análise de dados e geração de relatórios. Por fim, dos principais resultados obtidos com estas alterações, pode-se destacar a redução de tempo do processo em aproximadamente $17 \%$, a melhoria de alocação de recursos e o aumento de produtividade em aproximadamente $20 \%$. O balanceamento de linha proporcionou também a redução da ociosidade dos funcionários, devido a distribuição de atividades de trabalho, sem acúmulo de estoques intermediários e com menos colaboradores por célula, além de reduzir as paradas não planejadas. Assim, o trabalho contribui para a geração de resultados positivos ao processo, permitindo ganhos de produtividade $\mathrm{e}$ redução de custos com a melhoria dos indicadores, permitindo a potencialização dos resultados com a continuidade da aplicação das ferramentas.

\section{ABSTRACT}

Competitiveness in the various industrial segments has encouraged organizations to develop ways to make their operations and production processes more and more efficient and with greater productivity. With this, the companies look for characteristics that allow to have good results in relation to the competition. Thus, this study presents concepts about the application of tools, adequacy of layout and techniques for solving problems, improving the productive efficiency in a production line, ensuring the increase of quality and production by the productivity index and reduction of waste, in a medical products industry. The methodology for the application of process improvement tools was divided into stages, starting with the definition of a theoretical conceptual framework, followed by case planning, pilot testing, data collection, data analysis and reporting. The main results obtained with these changes, we can highlight the reduction of process time by approximately $17 \%$, the improvement in resource allocation, the increase in productivity by approximately 20\%. Line balancing also reduced employee idleness, due to the distribution of work activities, without accumulating intermediate stocks and with fewer employees per cell. In addition to improving production availability and reducing unplanned downtime. Thus, the work contributes to the generation of positive results to the process, allowing productivity gains and cost reductions with the optimization of the indicators, allowing the potentializing of the results with the continued application of the tools. 

um estudo de caso em uma indústria de produtos médicos. Brazilian Journal of Production Engineering, 6(7), 68-89.

\section{INTRODUÇÃO}

A concorrência faz com que as empresas tenham necessidade de realizar um melhor desempenho tanto de produtos como a forma de produzi-los com custos competitivos. Para se manterem no mercado, há uma importância significativa ter um gerenciamento de processos produtivos onde buscam um ganho na produtividade, evitando falhas e perdas durante os processos, fazendo com que equipamentos estejam sempre disponíveis para produção (Fogliatto, 2009; Oliveira, et al., 2019).

$\mathrm{O}$ aumento da competitividade entre as organizações tanto no mercado nacional como internacional, faz com que as estas busquem melhorias nos seus processos e operações, para gerar mais eficiência. Assim, as empresas sentem necessidade de explorar novos sistemas e modelos de produção para poder implantá-los, pensando em um resultado que possa trazer qualidade, tempo, baixo custo, flexibilidade e inovação (Antunes, 2009).

O uso de ferramentas da qualidade, identificando e analisando possíveis problemas, com o intuito de solucioná-los, por meio da implantação uma nova melhoria que reduza os desperdícios, promova o trabalho em equipe, são de fundamental importância para que técnicas para alavancar a produção seja alcançada (Garau, \& Pavan, 2018; Sharma, \& Patricia, 2003; Rodrigues, et al., 2020).

Para que as células de produção alcancem as exigências para quais foram projetadas, foi desenvolvido um estudo de caso, para analisar qual a melhor forma de garantir um aumento de produtividade, elevando a qualidade dos produtos, diminuindo custos e eliminando atividades que não agregam valor para o cliente, por meio de uma alteração de layout.

As características do layout estão diretamente ligadas aos objetivos das empresas. Tornando assim as atividades menos complexas, auxiliando para o bem-estar produtivo, proporcionando um melhor fluxo de informações. Para Martins e Laugeni (2005), a disposição de layout é uma atividade multidisciplinar, que envolve diversas áreas da organização, justificando a importância de sua utilização de todos na definição do arranjo físico, principalmente nas etapas de verificação e determinação de soluções.

Conforme trabalhos de Moreira (2008), Kikolski e Ko (2018) e Santos e Reis (2019), estudos sobre layout são de grande importância, gerando resultados de produtividade, conforme Liu et al. (2019) apontam em seu estudo, ou de qualidade, conforme aborda Curi (2020). Levando em consideração a contribuição dos autores citados, fica explícita a importância de analisar o layout de um processo produtivo, além de compreender até que ponto a disposição de recursos podem interferir nos níveis de produtividade (e nas demais variáveis) que são importantes para que sejam alcançados os objetivos de uma empresa (Rodrigues, et al., 2020b).

O desenvolvimento do trabalho foi em uma indústria de dispositivos e produtos médicos em uma empresa situada em São Sebastião do Paraíso, Minas Gerais. O tema abordado refere-se à aplicação de ferramentas para uma mudança de layout em uma célula de produção de fios de suturas cardiovasculares.

Assim, esta pesquisa busca responder a seguinte pergunta: Como melhorar a eficiência produtiva, por meio de uma adequação de layout, para garantir o aumento da produção pelo 
Citação (APA): Amorin, L., Rodrigues, T. V., \& Silva Junior, J. F. da. (2020). Melhoria de eficiência produtiva de uma linha de produção: um estudo de caso em uma indústria de produtos médicos. Brazilian Journal of Production Engineering, 6(7), 68-89.

índice de produtividade e redução de desperdícios?. Assim o objetivo desta pesquisa é adequar o layout do processo produtivo de uma indústria de produtos médicos buscando melhorar a eficiência produtiva, e o aumento da qualidade e produção por meio do índice de produtividade e redução de desperdícios.

Para atingir este objetivo serão seguidos os seguintes passos: Avaliar os tempos de produção, por meio da cronoanálise e heijunka; Compreender o estado atual da linha de montagem de fabricação, por meio de um Brainstorming; Reconhecer a parte principal do desperdício, problema e chances entre o processo, por meio da ferramenta A3, para propor um layout adequado; Reduzir desperdício de movimentação e atividades que não agregam valor no processo produtivo, com o balanceamento de linha no layout celular em "U"; Efetuar a mudança para layout Celular em formato de "U".

Este trabalho foi estruturado em cinco capítulos. O Capítulo 1, Introdução, apresenta uma breve contextualização sobre o cenário da Indústria 4.0, assim como o Problema de Pesquisa, Objetivo Geral, Específicos e Justificativa do estudo. Em seguida, é apresentada a relação da engenharia de produção com o tema proposto. O Referencial Teórico, segundo capítulo, aborda a revisão bibliográfica em torno da temática layout, produtividade e qualidade. $\mathrm{O}$ Capítulo 3 apresenta o método da pesquisa. Sendo dividida em caracterização da pesquisa e método de realização das atividades. O quarto capítulo apresenta os resultados e discussões do trabalho. Por fim, a Conclusão aponta as considerações finais sobre o estudo, bem como as limitações, fragilidades, dificuldades para elaboração e sugestões para trabalhos futuros.

\section{REFERENCIAL TEÓRICO}

\subsection{LAYOUT}

O layout é a maneira como os recursos se encontram distribuídos fisicamente dentro de uma instalação, podendo ser considerados recursos transformados (matéria prima, informações e clientes) ou transformadores (máquinas, equipamentos e operadores) (Moreira, 2008; Kikolski, \& Ko, 2018; Santos, \& Reis, 2019). Denominado também como arranjo físico, é definido como o posicionamento de recursos transformadores em relação aos outros e como as atividades do processo serão distribuídas a esses recursos, esse posicionamento é responsável por padronizar o fluxo de recursos transformados conforme o processo acontece (Slack, et al., 2009).

As características do layout estão diretamente ligadas aos objetivos das empresas. Torna-se assim as atividades menos complexas, auxiliando para o bem-estar produtivo e proporcionando um melhor fluxo de informações. Para Martins e Laugeni (2015), a disposição do arranjo físico é uma atividade multidisciplinar, que envolve diversas áreas da organização, justificando a importância de sua utilização de todos na definição do arranjo físico, principalmente nas etapas de verificação e determinação de soluções.

Para desenvolver um projeto de layout que atenda às necessidades de uma empresa, é preciso compreender os tipos básicos de layouts existentes que são: por processo; em linha; celular; por posição fixa e misto ou combinado (Martins, \& Laugeni, 2015; Liu, et al., 2019; Rodrigues, et al., 2019). Os tópicos 2.2.1 a 2.2.5 irão conceituar tais tipos de layouts.

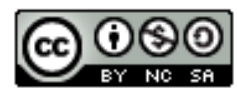



um estudo de caso em uma indústria de produtos médicos. Brazilian Journal of Production Engineering, 6(7), 68-89.

\subsubsection{LAYOUT POR PROCESSO}

Também chamado de layout funcional, este arranjo físico se adequa às necessidades das atividades realizadas pelos recursos (transformadores ou transformados) que compõe o processo (Slack, et al., 2009). Deste modo os processos são agrupados próximos a processos similares, de forma a compartilhar os recursos a serem transformados. O agrupamento dos recursos transformadores em famílias é capaz de oferecer maior facilidade na sua estocagem e reposição (Liu, et al., 2019).

Seguindo esta linha de raciocínio, esse tipo de arranjo físico agrupa todos os processos e equipamentos similares em uma área comum, assim como as atividades semelhantes, portanto quem se desloca é o material (Martins, \& Laugeni, 2015; Liu, et al., 2019).

\subsubsection{LAYOUT EM LINHA}

Proposto por Henry Ford em 1939, e pioneiro entre os arranjos físicos, o layout em linha é muito utilizado na indústria e também por algumas organizações prestadoras de serviços (Peinado, \& Graeml, 2007). O layout em linha é aquele em que os recursos transformadores são distribuídos em sequência conforme as operações, de acordo com a sequência de execução estabelecida.

Este arranjo físico, também é indicado para produção com pouca ou nenhuma variação, objetivando atingir grande volume de produção, alcançando assim economia de escala (Martins, \& Laugeni, 2015; Liu, et al., 2019).

\subsubsection{LAYOUT CELULAR}

O layout celular é definido como o arranjo que aloca em um mesmo espaço físico máquinas diferentes que possam fabricar o produto inteiro. Portanto o material transita dentro da célula até os processos necessários. $\mathrm{O}$ arranjo físico originou-se de uma necessidade de tornar o processo de fabricação mais flexível, com relação a do fluxo de materiais e operacional (Martins, \& Laugeni, 2015; Liu, et al., 2019).

Este tipo de layout busca unir as vantagens do arranjo físico por processo com as vantagens do layout por produto. Assim, é possível obter a redução do lead time, dos inventários, dos lotes de transferência de um equipamento ou posto de trabalho a outro, e ainda permite que um único funcionário atue em postos distintos (Seixas, 2014).

\subsubsection{LAYOUT POR POSIÇÃO FIXA}

Considerado por Slack, et al., (2009) um arranjo físico um tanto quanto contraditório, o layout por posição fixa é um processo onde os recursos transformados não se movem entre os recursos transformadores. Assim quem sofre o processamento fica parado, enquanto os recursos transformadores se movem na medida do necessário.

Os recursos aplicados ao produto são dispostos próximos ao mesmo, conforme abordam. $\mathrm{O}$ produto, portanto, não se move, a matéria-prima é fornecida de um lado e os recursos são localizados próximos ao local de produção (D’Agostini, et al., 2014).

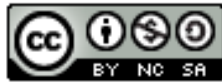



um estudo de caso em uma indústria de produtos médicos. Brazilian Journal of Production Engineering, 6(7), 68-89.

Trata-se então de um layout recomendado em casos de produção de um produto único, em pequena quantidade ou unitário e, geralmente, não repetitivo, como são os casos de fabricação de navios, pontes rolantes, entre outros produtos de grandes dimensões físicas (Martins, \& Laugeni, 2015; Liu, et al., 2019).

\subsubsection{LAYOUT MiSTO OU COMBINADO}

A utilização de layouts combinados, segundo Martins e Laugeni (2015), ocorre para aproveitar em um determinando processo as vantagens do layout funcional e da linha de montagem. Slack, et al., (2009) afirmam que são muitas as operações que usam o layout misto, combinando elementos de alguns ou todos os tipos básicos de arranjo físico em diferentes partes da operação. Os autores ainda usam como exemplo o arranjo físico de um hospital, que normalmente seria funcional, entretanto, cada departamento, diferentes arranjos físicos são utilizados.

Da mesma forma que não há apenas um tipo a ser considerado o melhor layout para todas as indústrias, é possível que dentro de uma mesma indústria não haja um único arranjo produtivo que atenda todas as suas necessidades. Portanto, o layout misto é uma solução inteligente para potencializar os ganhos e minimizar as perdas na escolha do arranjo físico de produção (D’Agostini, et al., 2014).

\subsection{FERRAMENTAS E TÉCNICAS de ANÁlISE E SOLUÇÃO DE PROBLEMAS}

São processos realizados para identificar e executar ações corretivas para problemas complexos, adotando métodos científicos em uma abordagem analítica. Para uma resolução eficaz é preciso que o problema seja identificado e totalmente compreendido pelos gestores. Posteriormente, diversas técnicas de solução podem ser usadas para reduzir a causa raiz do problema e tomar as ações corretivas apropriadas para não apenas corrigir a avaria, mas também para garantir que ele não ocorra novamente. Existem muitas ferramentas e abordagens de solução de problemas que são eficazes se usadas adequadamente (Santos, 2019). Dentre todas, o estudo focou nas ferramentas: A3; Heijunka; Cronoanálise; Brainstorming e 5W2H, que serão definidas nos tópicos 2.3.1 a 2.3.5.

\subsubsection{A3 (PROBLEM SOLVING)}

A ferramenta A3, exemplificada na Figura 1, é uma abordagem sistemática para a solução de problemas em um único pedaço de papel de tamanho A3. Esta auxilia na elucidação das dúvidas e a orientação para a resolução do mesmo (Saad, et al., 2013). Ele também tem o potencial de aumentar bastante a taxa de aprendizado organizacional e se tornar um catalisador para a transformação em uma organização verdadeiramente continuamente aprimorada (Sobek II, \& Jimmerson, 2004). 

um estudo de caso em uma indústria de produtos médicos. Brazilian Journal of Production Engineering, 6(7), 68-89.

Figura 1. Exemplo de A3.

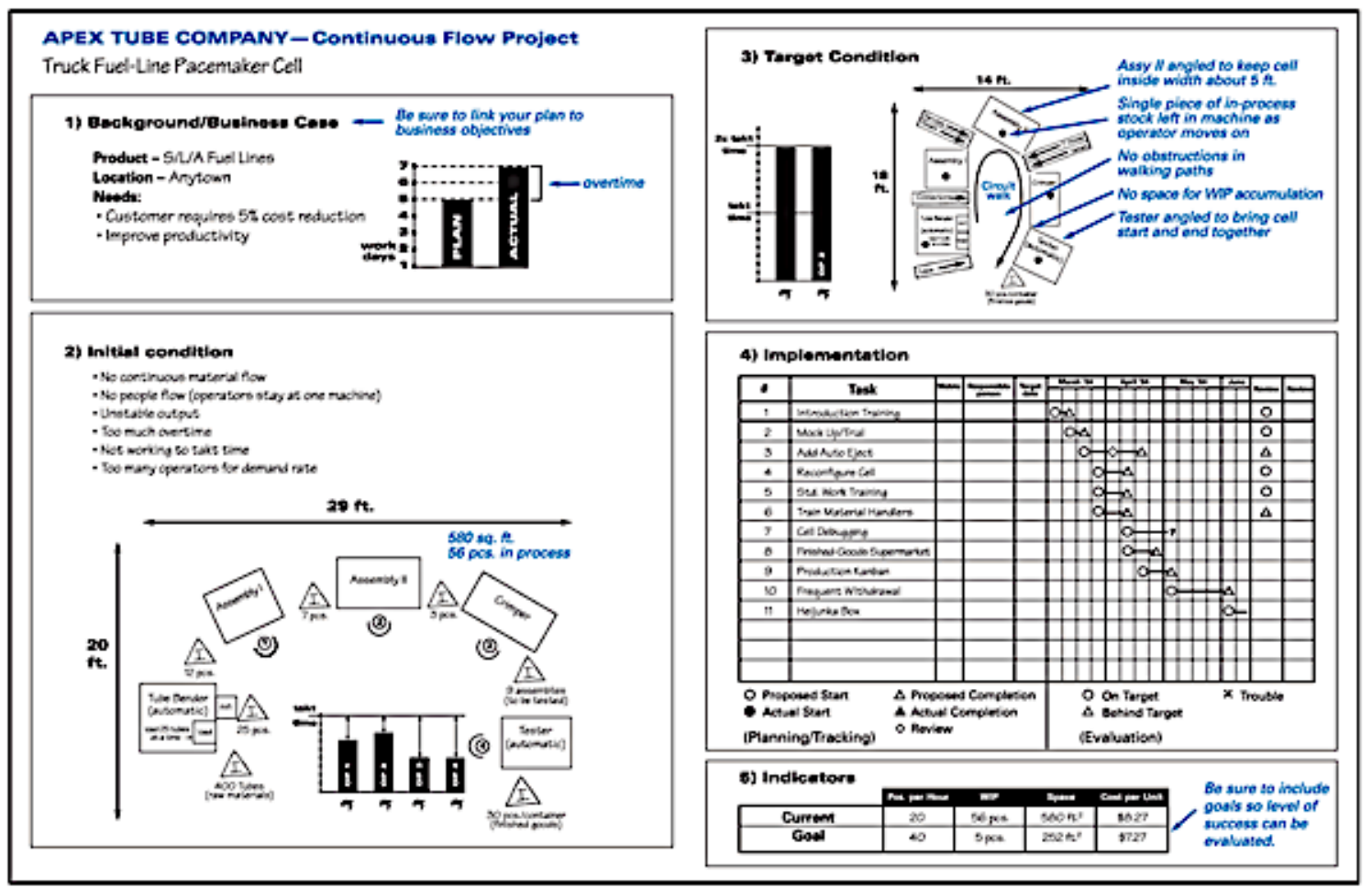

Fonte: Adaptado de Lean Enterprise Institute (2019).

A ferramenta A3 é representado pelo fornecimento dos sete elementos principais a seguir (SAAD, 2013):

- Declaração da questão: um título descritivo para o relatório;

- Antecedentes do problema: informações relevantes para conectar o problema ao contexto organizacional e histórico mais amplo;

- Condição atual: um diagrama icônico que descreve como o processo atualmente funciona, com o (s) principal (s) problema (s) rotulado (s) e dados que descrevem a extensão do problema (por exemplo, porcentagem de pedidos recebidos com atraso);

- Análise de causa: cadeia de causa e efeito que leva à raiz do problema;

- Condição alvo: contramedida proposta (s) para a causa raiz, um diagrama icônico que descreve como o novo processo funcionará com a contramedida proposta (s) implementada (s) e o desempenho previsto;

- Plano de implementação: as ações necessárias para realizar a condição de destino, quem executará cada ação e quando;

- Plano de acompanhamento: como e quando o usuário verificará se a condição de destino foi realizada e se os resultados previstos foram alcançados;

- Resultados: os resultados reais da implementação (deixados em branco inicialmente).

\subsection{DESPERdícios da Produção}

Os princípios, técnicas e ferramentas da Produção Enxuta tem a finalidade de eliminar as perdas no processo produtivo. Partindo desses princípios, Taiichi Ohno foi quem identificou inicialmente as sete principais perdas que ocorrem nos processos industriais: superprodução;

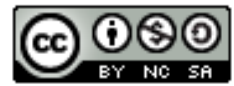



um estudo de caso em uma indústria de produtos médicos. Brazilian Journal of Production Engineering, 6(7), 68-89.

processamento; retrabalho; movimentação excessiva; espera; estoque; transporte (Albertin, \& Pontes, 2016; Radhakrishnan, et al., 2019).

- Superprodução: Segundo Ohno (1997), a superprodução representa a pior das perdas, pois tende a esconder outras perdas, como, as perdas por produção de produtos defeituosos e as perdas derivadas da espera do processo e espera do lote. A superprodução pode ser dividida em dois tipos: quantitativa, que geralmente ocorre quando as empresas produzem itens para os quais não existe demanda, ou a produção mais do que o necessário com o intuito de prevenção. Há também a superprodução antecipada que ocorre quando os produtos não são produzidos no momento certo, mas sim produzidos antecipadamente não seguindo um cronograma pré-estabelecido (Shingo, 1996; Chiarini, et al., 2018);

- Processamento: Ações desnecessárias no processo que poderiam ser eliminadas sem alterar as características do produto podem ser consideradas perdas por processamento. Que ocorre por falhas de projetos ou restrições nos processos e máquinas, decorrente desse mal planejamento geradas durante o processamento do produto, que consequentemente não agrega valor ao cliente final. Devem ser aplicadas técnicas de engenharia e análise de valor utilizando-se da racionalidade com o intuito de otimizar o processamento (Albertin, \& Pontes, 2016; Chiarini, et al., 2018; Radhakrishnan, et al., 2019);

- Retrabalho: considerado como a mais visível perda, por se tratar de fabricação de produtos defeituosos e a fabricação de produtos que não atendem as especificações do cliente. Esses produtos não conformes precisarão ser retrabalhados ou em último caso descartados, o que irá gerar custos desnecessários a produção (Albertin; Pontes, 2016; Radhakrishnan et al., 2019);

- Movimentação excessiva: As perdas por movimentação devem ser associadas aos movimentos desnecessários realizados pelos operários e pelas máquinas na execução de uma operação no ambiente fabril. Essa forma de perda pode ser eliminada por meio da adoção de melhorias baseadas no estudo de tempos e movimentos (Albertin, \& Pontes, 2016; Radhakrishnan, et al., 2019);

- Espera: As perdas por espera são associadas aos intervalos de tempo nos quais os operários ou as máquinas não estão sendo aproveitadas produtivamente. Assim a empresa acaba não utilizando a capacidade total da sua mão de obra e equipamentos para agregar valor à empresa. Para se combater esse tipo de desperdício pode-se utilizar ferramentas voltadas a gestão dos postos de trabalho e mais amplamente, utilizar a manutenção produtiva total (Antunes, 2008; Chiarini, et al., 2018);

- Estoque: O elevado nível de matérias primas, material em processo e produtos acabados são considerados perdas por estoque. Esse estoque gera custos financeiros e necessitarão de maior espaço físico por ocuparem mais lugar por mais tempo. O Sistema Toyota de Produção procura reduzir ordenadamente e continuamente os estoques por meio de uma política de melhoria contínua, busca equiparar a capacidade de produção versus a demanda a partir da sincronização da produção (Antunes, 2008; Radhakrishnan, et al., 2019);

- Transporte: Devido a ser uma atividade que não agrega valor, o transporte pode ser visto como uma perda que deve ser minimizada ou se possível eliminada completamente. Essa perda ocorre devido a inadequada movimentação dos materiais durante o processo. É possível diminuir esse tipo de perda efetuando melhorias no layout e sempre tentar montar as células de produção de forma a fazer com que a movimentação dos materiais seja a mínima possível (Albertin, \& Pontes, 2016; Radhakrishnan, et al., 2019).

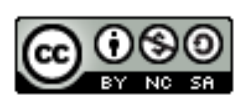



um estudo de caso em uma indústria de produtos médicos. Brazilian Journal of Production Engineering, 6(7), 68-89.

\section{MÉTOdO DE PESQUISA}

Para que o objetivo fosse alcançado, este trabalho foi estruturado quanto as etapas descritas por Miguel (2007). Dividido em seis etapas, a proposta para se conduzir uma pesquisa por meio de um estudo de caso é relacionada às atividades apresentadas no Quadro 1.

Quadro 1. Proposta para se conduzir uma pesquisa por meio de um estudo de caso

\begin{tabular}{|c|c|}
\hline Atividade & Descrição \\
\hline $\begin{array}{l}\text { Definir uma estrutura } \\
\text { conceitual teórica }\end{array}$ & $\begin{array}{c}\text { Mapear a literatura acerca do tema, delinear as proposições, delimitar as } \\
\text { fronteiras e grau de evolução; }\end{array}$ \\
\hline Planejar os casos & $\begin{array}{l}\text { Selecionar as unidades de análise e contatos, escolher os meios para coleta } \\
\text { e análise dos dados, definir meios de controle da pesquisa; }\end{array}$ \\
\hline Conduzir teste piloto & $\begin{array}{l}\text { Testar procedimentos de aplicação, verificar a qualidade dos dados, fazer os } \\
\text { ajustes necessários; }\end{array}$ \\
\hline Coletar os dados & Contatar os casos, registrar os casos, limitar os efeitos do pesquisador; \\
\hline Analisar os dados & $\begin{array}{c}\text { Produzir as narrativas, reduzir os dados, construir painel, identificar } \\
\text { causalidade; }\end{array}$ \\
\hline Gerar relatório & Desenhar implicações teóricas, prover estrutura para replicação. \\
\hline
\end{tabular}

Fonte: Adaptado Miguel (2007).

A fase de definição de uma estrutura conceitual teórica implica em pesquisas e embasamentos nas diversas literaturas referentes ao tema a ser abordado nos trabalhos científicos. Os principais meios de pesquisas foram: artigos; monografias; sites; normas; entre outros. Foram analisados principalmente artigos dos últimos 10 anos.

Então, foi feito um levantamento bibliográfico a respeito dos trabalhos referentes a layout e técnicas de análise e solução de problemas. Por meio desta pesquisa, e a utilização das ferramentas analisadas, pôde-se perceber o grau de importância da aplicação deste conceito na melhoria de eficiência produtiva de uma linha de produção. Além da necessidade de melhoria da empresa, observou-se também, a relevante quantidades de estudos sobre o tema de pesquisas, o que motivou a realização do presente trabalho, segundo os resultados satisfatórios apresentados.

$\mathrm{Na}$ fase de planejamento do caso foram levantados os problemas em torno do caso estudado, demonstrando de maneira clara a razão para se desenvolver o modelo do estudo. Definem-se também os objetivos desejados, pelo pesquisador para que o modelo proposto possa alcançalos ao final de seu processo.

Inicialmente uma única empresa foi analisada. Em seguida foi realizada uma reunião para discutir o problema. Por fim foi realizada uma análise e mensuração do processo, buscando entender a linha e avaliar um possível nivelamento do processo. Para esta fase serão utilizadas as ferramentas de Cronoanálise, Brainstorming e Heijunka. As ferramentas citadas acima serão utilizadas para solucionar o problema identificado no setor analisado.

O terceiro passo, condução do teste piloto, realiza-se por meio de um protótipo em papelão, para simular e discutir sobre as principais causas do projeto. Algumas pessoas deixam de realizar o teste piloto, normalmente por levar tempo, mas é uma etapa do processo que não pode ser ignorada, já que é onde surge a oportunidade de que, antes da aplicação maciça, possam ser identificados pequenos problemas.

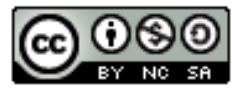



um estudo de caso em uma indústria de produtos médicos. Brazilian Journal of Production Engineering, 6(7), 68-89.

$\mathrm{Na}$ coleta de dados, os dados foram coletados por meio de documentos da empresa, observação visual do processo e anotações na empresa alvo do estudo. Além das informações coletadas pela autora, por meio de uma reunião com os colaboradores responsáveis da engenharia de processos e do setor analisado e adicionadas a uma planilha do Excel, para ter um controle dos resultados obtidos.

O foco desta observação foi identificar os pontos problemas do processo. Por meio de coleta de dados levantou-se características da empresa, para a identificação de possíveis problemas no processo. Esta coleta permitiu a determinação das ferramentas e técnicas a serem utilizadas na melhoria do processo. As ferramentas utilizadas foram Cronoanálise, Balanceamento do processo e Heijunka

Após a coleta dos dados, e aplicação das atividades de melhoria, foi feita uma filtragem dos dados com o objetivo de se obter apenas os dados mais relevantes para condução do estudo, assim como as ações a serem efetuadas para a implementação das soluções no processo. Para o levantamento do problema este trabalho está focado em reuniões, brainstorming, com envolvidos para listar os objetivos, equipes, dificuldades e atitudes a concretizar o trabalho de melhoria. Assim foi definida as atitudes a serem tomadas para atingir os objetivos específicos (Figura 2).

Figura 2: Planejamento do caso

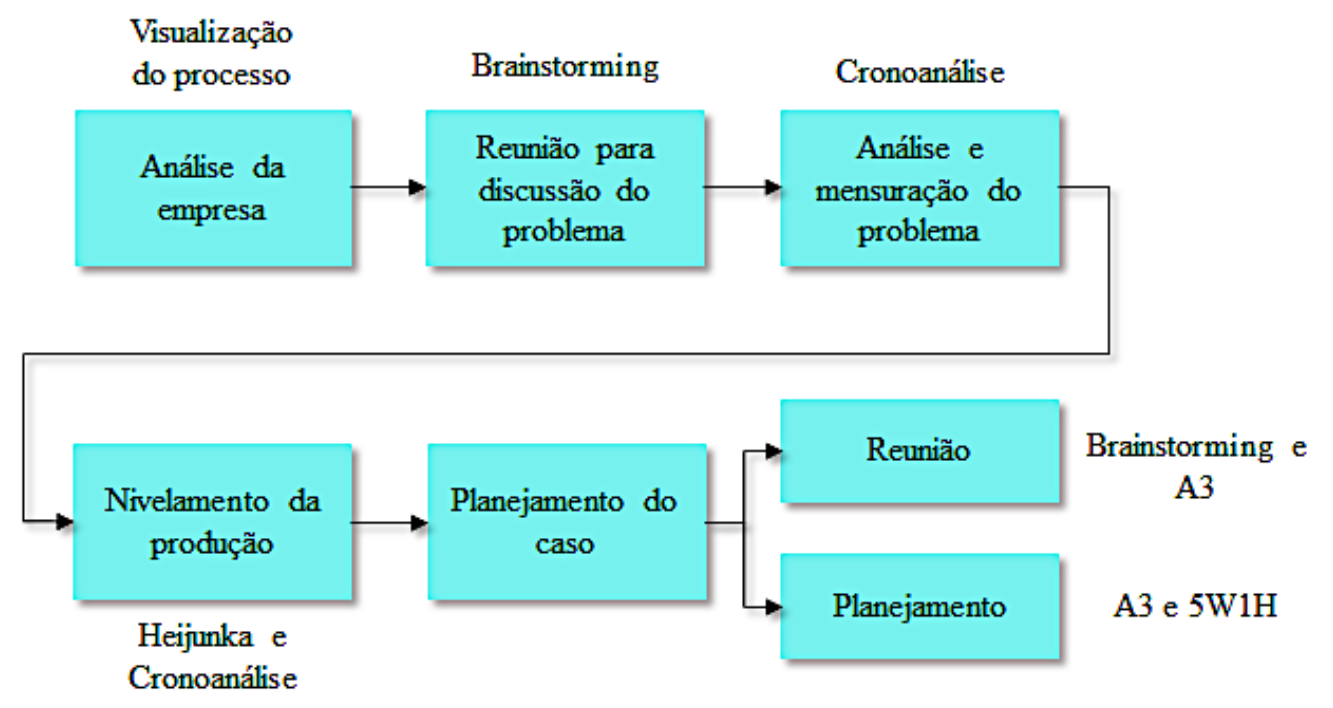

Fonte: Autores (2020)

Por fim, por meio de planilhas de Excel, e de forma textual do presente trabalho, foram apresentados os resultados obtidos na aplicação da melhoria de eficiência produtiva de uma linha de produção de produtos médicos.

\section{ReSUltados E DiscuSSÃo}

A pesquisa de campo foi realizada em uma empresa de produtos e dispositivos médicos, em uma linha de produção de fios de suturas cardiovasculares. É uma organização multinacional que sempre está em busca de melhoria contínua. Um estudo de caso foi realizado para analisar e coletar os dados do novo processo de fabricação que foi implantado. No presente estudo foi empregado o método quanti-qualitativo, pois os dados adquiridos serão numéricos 
Citação (APA): Amorin, L., Rodrigues, T. V., \& Silva Junior, J. F. da. (2020). Melhoria de eficiência produtiva de uma linha de produção: um estudo de caso em uma indústria de produtos médicos. Brazilian Journal of Production Engineering, 6(7), 68-89.

(quantitativos) e qualitativos em relação a linha de produção, a fim de realizar uma comparação entre a produtividade atual, com a produtividade que se pretende adquirir com esse novo método de produção.

A empresa analisada apresenta um problema relacionado a demora para iniciar a produção, pois a atividade inicial, onde as espumas são coladas nos rótulos internos, demandava muito tempo, e para agilizar essa atividade uma colaboradora ficava responsável por colar as espumas nos rótulos internos em uma outra célula separada para ir abastecendo a célula posteriormente. Também as colaboradoras durante o processo de setup, também ajudavam a colar a espuma no rótulo interno, enquanto a regulagem da máquina era feita. Essas eram preparadas em grande quantidade, para evitar paradas no decorrer do período de trabalho.

Para iniciar uma nova ordem de manufatura era realizado o setup do processo, para trocas de máquinas de encastoamento era realizado por uma colaboradora externa a célula, a colaboradora do SMED, onde fazia as trocas de máquinas já reguladas ou também realizava a regulagem na própria célula quando necessário. Enquanto a regulagem era feita, as colaboradoras já iam retirando os produtos da ordem anterior, realizando a assepsia das mesas, realizava a conferência de lotes e quantidades certas de matérias primas, e deixava todo o material necessário na célula para ir pegando conforme fossem usando. Leva-se em torno de 20 a 30 minutos.

O processo posterior, denominado de encastoamento, no qual o fio é colocado na agulha, e por meio de uma máquina mecânica, é realizado a junção de ambos, em seguida a mesma colaboradora coloca o fio já encastoado no carrossel. A segunda etapa que é realizada por uma outra colaboradora, a agulha é espetada na espuma e o fio embalado no rótulo interno, e em seguida o envelopamento, o que resultava em um grande número de envelopes sem selar, para serem selados de uma vez no final do processo. Um problema nessa etapa era que a colaboradora da $1^{\circ}$ etapa podia ser muito rápida, sobrecarregando a $2^{\circ}$ operadora. Com isso a $1^{\circ}$ colaboradora necessita paralisar seu processo para ajudar a espetar as agulhas ou a envelopar.

A colaboradora da $2^{\circ}$ etapa, também pode ser mais rápida e ter que ficar esperando produto da $1^{\circ}$ etapa. Nessa célula de produção existem 2 colaboradoras para a $1^{\circ}$ etapa e 2 colaboradoras para $2^{\circ}$ etapa, necessitando de uma outra colaboradora para realizar a selagem dos produtos no final de cada ordem. Sendo assim, 5 colaboradoras para realizar as atividades em uma única célula de produção. Com base na descrição deste processo, foram realizadas uma série de ações para tentar solucioná-lo. O Quadro 2 apresenta os desperdícios identificados no processo. 
Citação (APA): Amorin, L., Rodrigues, T. V., \& Silva Junior, J. F. da. (2020). Melhoria de eficiência produtiva de uma linha de produção: um estudo de caso em uma indústria de produtos médicos. Brazilian Journal of Production Engineering, 6(7), 68-89.

Quadro 2. Desperdícios identificados no processo

\begin{tabular}{|c|l|l|}
\hline \multicolumn{2}{|c|}{ Desperdício } & Problemas \\
\hline & Superprodução & Desperdícios por superprodução \\
\hline & Processamento & Embalagens preparadas em grande quantidade no início do processo \\
(empilhamento)
\end{tabular}

Fonte: Autores (2020).

A empresa preza por sua melhoria contínua, na busca por formas de melhorar o seu desempenho, por isso foi realizado uma pesquisa no mercado internacional, para a mudança de layout, em busca de novos processos de fabricação que teve o seu desempenho melhorado, para poder realizar a implantação desse novo sistema de produção.

\subsection{IdenTIFICAÇÃo do Problema}

Em um primeiro momento foi realizado uma visita na área a ser analisada da empresa alvo do estudo, onde foi apresentado pelos responsáveis a descrição do processo produtivo, apresentado na figura 3, que foi melhor elucidada após a visualizações do processo. Nesta etapa, um brainstorming foi realizado, com todos os envolvidos no projeto, sendo colaboradores e gestores. Inicialmente uma roda livre de conversas focadas ao problema foi realizada, onde as informações obtidas foram tabeladas e arquivadas para usos futuros. Em seguida as críticas e ideias mais complexas foram descartadas. Busca-se a combinação das convicções para a melhoria do processo.

Esta ferramenta, adequada aos passos de Osborne (1957), e já utilizada pela empresa, auxiliou na identificação de um problema inicial que seria a falta de um balanceamento de linha. Outro ponto a se destacar foi a observação de produtos desperdiçados durante o processo, que poderiam ser processados indevidamente pelas colaboradoras, o que resultava em perdas no processo. Vale ressaltar que esta etapa de aplicação da ferramenta foi ministrada pelo responsável da área.

Assim, em conjunto com a equipe do projeto definiu-se que, para analisar este problema seria necessário a realização de cálculos de cronoanálise, conforme definição de Sotsek e Bonduelle (2017). Buscou-se medir e analisar o tempo que o operador leva para realizar determinada ação no fluxo de produção (levando em consideração o tempo de tolerância para necessidades como, quebras de maquinário e outros).

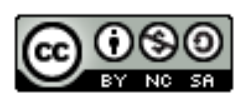



um estudo de caso em uma indústria de produtos médicos. Brazilian Journal of Production Engineering, 6(7), 68-89.

Figura 3. Fluxograma do processo

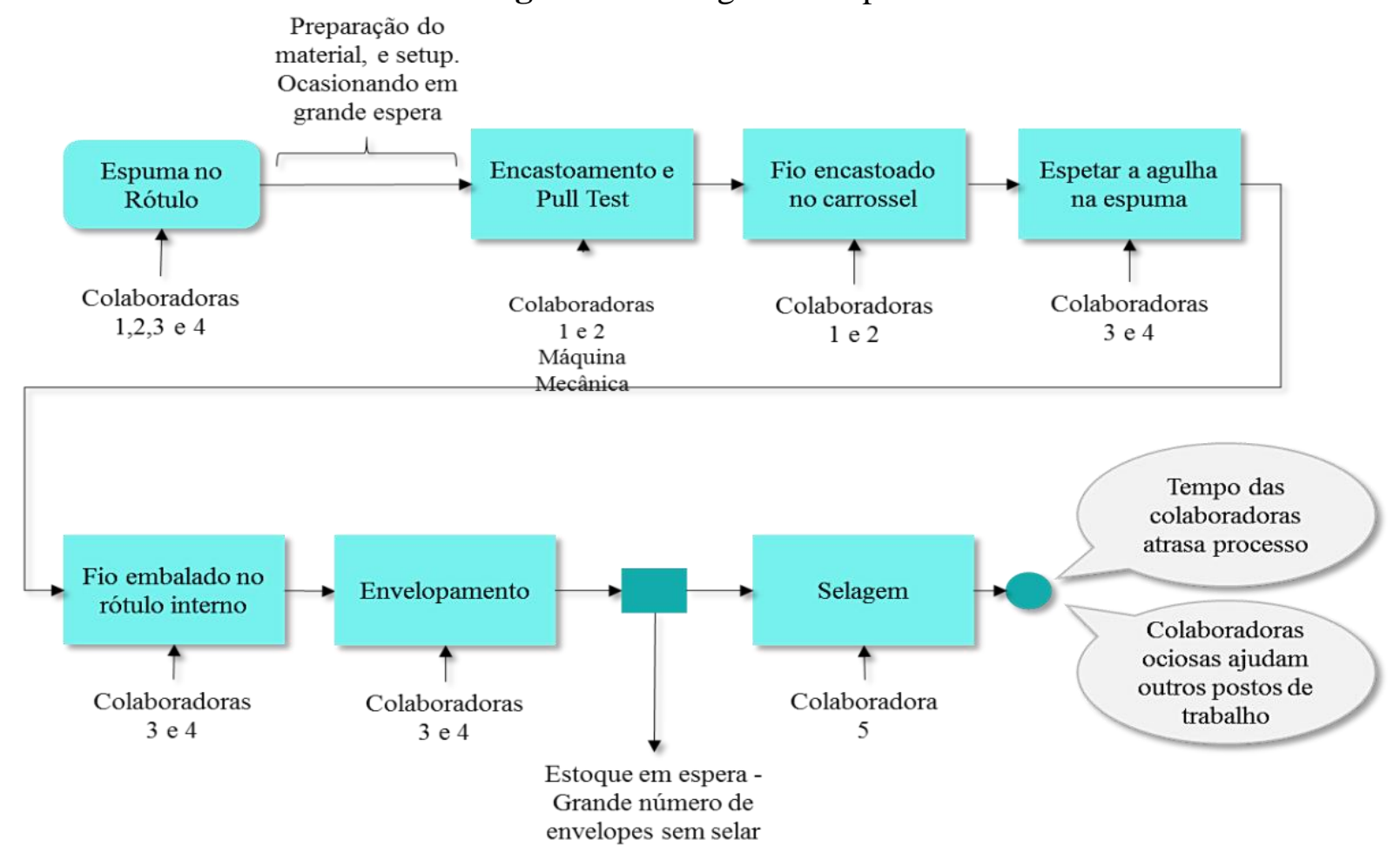

Fonte: Autores (2020).

Para cronoanálise, utilizou-se uma tabela, já utilizada pela empresa para coletar os dados do processo. Esta etapa se enquadra na ferramenta Heijunka, que foi implantado para proporcionar um controle de quanto deve produzir por hora. Utilizado para melhorar o gerenciamento da produção, com o intuito de possibilitar o fluxo contínuo. Elimina-se assim os estoques intermediários a cada fase da produção. Visando reduzir o tempo de espera entre os processos.

\subsubsection{PlaneJAMENTO DO CASO}

Após a identificação do problema foram avaliadas as possíveis soluções. A aplicação da cronometragem do processo da célula analisada, foi realizada pela engenharia, durante todo o processo produtivo, contabilizando mais de 20 tempos (Tabela 1), os maiores tempos são representados por vermelho e os menores em verde. Estas medições possibilitaram aos envolvidos obterem uma visão mais clara sobre o problema. 

um estudo de caso em uma indústria de produtos médicos. Brazilian Journal of Production Engineering, 6(7), 68-89.

Tabela 1. Cronometragem antes das alterações de layout (em segundos)

\begin{tabular}{|c|c|c|c|c|c|c|c|c|c|c|c|c|c|c|c|c|c|c|}
\hline \# & 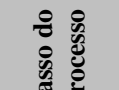 & $\approx$ & \multicolumn{15}{|c|}{ Tempo coletado } & 苞 \\
\hline \multirow{3}{*}{1} & \multirow{3}{*}{ 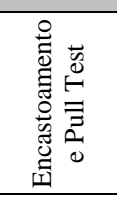 } & \multirow{3}{*}{$\begin{array}{l}0 \\
0 \\
0 \\
\tilde{\Xi} \\
0 \\
0 \\
0\end{array}$} & 24,40 & $\begin{array}{c}20,1 \\
1\end{array}$ & $\begin{array}{c}18,8 \\
5\end{array}$ & $\begin{array}{c}20,4 \\
2\end{array}$ & $\begin{array}{c}18,8 \\
9\end{array}$ & $\begin{array}{c}21,7 \\
8\end{array}$ & $\begin{array}{c}19,9 \\
8\end{array}$ & $\begin{array}{c}25,0 \\
5\end{array}$ & $\begin{array}{c}20,0 \\
7\end{array}$ & $\begin{array}{c}19,9 \\
4\end{array}$ & $\begin{array}{c}20,8 \\
0\end{array}$ & $\begin{array}{c}21,1 \\
9\end{array}$ & $\begin{array}{c}19,2 \\
0\end{array}$ & 24,78 & $\begin{array}{c}17,9 \\
4\end{array}$ & \multirow{3}{*}{20,90} \\
\hline & & & 23,73 & $\begin{array}{c}17,4 \\
6 \\
\end{array}$ & $\begin{array}{c}25,7 \\
3 \\
\end{array}$ & $\begin{array}{c}18,8 \\
6 \\
\end{array}$ & $\begin{array}{c}18,8 \\
6 \\
\end{array}$ & $\begin{array}{c}23,0 \\
4 \\
\end{array}$ & $\begin{array}{c}20,4 \\
6 \\
\end{array}$ & $\begin{array}{c}19,1 \\
6 \\
\end{array}$ & & & & & & & & \\
\hline & & & & & & & & & & & & & & & & & & \\
\hline \multirow{3}{*}{2} & \multirow{3}{*}{ 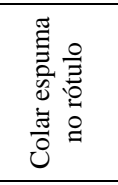 } & \multirow{3}{*}{ 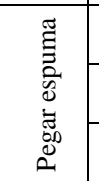 } & 3,89 & 2,94 & 3,52 & 3,47 & 3,45 & 4,47 & 3,61 & 2,68 & 3,48 & 3,55 & 5,20 & 3,34 & 4,03 & 3,30 & 4,51 & \multirow{3}{*}{3,83} \\
\hline & & & 3,12 & 8,18 & 3,47 & 5,84 & 3,51 & 2,90 & 2,94 & 2,94 & 3,47 & & & & & & & \\
\hline & & & & & & & & & & & & & & & & & & \\
\hline \multirow{3}{*}{3} & \multirow{3}{*}{ 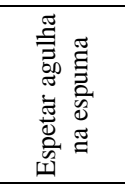 } & \multirow{3}{*}{$\begin{array}{l}\stackrel{0}{0} \\
0 \\
0 \\
0 \\
0 \\
0\end{array}$} & 7,40 & 5,38 & 4,13 & 6,34 & 6,38 & 3,97 & 5,37 & 5,51 & 5,77 & 4,97 & 4,56 & 5,38 & 6,10 & 6,02 & 5,60 & \multirow{3}{*}{5,52} \\
\hline & & & 5,17 & 4,99 & 7,20 & 5,90 & 4,78 & 4,88 & & & & & & & & & & \\
\hline & & & & & & & & & & & & & & & & & & \\
\hline \multirow{3}{*}{4} & \multirow{3}{*}{ 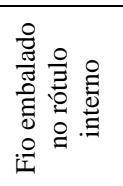 } & \multirow{3}{*}{ 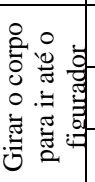 } & 12,55 & $\begin{array}{c}13,1 \\
6 \\
\end{array}$ & $\begin{array}{c}12,3 \\
1 \\
\end{array}$ & $\begin{array}{c}13,4 \\
3 \\
\end{array}$ & $\begin{array}{c}11,8 \\
7 \\
\end{array}$ & $\begin{array}{c}11,9 \\
5\end{array}$ & $\begin{array}{c}13,5 \\
7 \\
\end{array}$ & $\begin{array}{c}13,3 \\
1 \\
\end{array}$ & $\begin{array}{c}13,1 \\
2 \\
\end{array}$ & $\begin{array}{c}11,7 \\
9 \\
\end{array}$ & $\begin{array}{c}20,0 \\
2 \\
\end{array}$ & $\begin{array}{c}10,6 \\
9 \\
\end{array}$ & $\begin{array}{c}13,1 \\
3\end{array}$ & 11,78 & $\begin{array}{c}13,4 \\
2 \\
\end{array}$ & \multirow{3}{*}{13,53} \\
\hline & & & 11,95 & $\begin{array}{c}12,6 \\
4 \\
\end{array}$ & $\begin{array}{c}18,5 \\
1 \\
\end{array}$ & $\begin{array}{c}12,1 \\
3 \\
\end{array}$ & $\begin{array}{c}14,7 \\
3 \\
\end{array}$ & $\begin{array}{c}12,0 \\
6 \\
\end{array}$ & $\begin{array}{c}13,8 \\
1 \\
\end{array}$ & $\begin{array}{c}13,4 \\
8 \\
\end{array}$ & $\begin{array}{c}19,2 \\
4 \\
\end{array}$ & & & & & & & \\
\hline & & & & & & & & & & & & & & & & & & \\
\hline \multirow{3}{*}{5} & \multirow{3}{*}{ 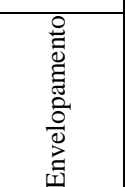 } & \multirow{3}{*}{ 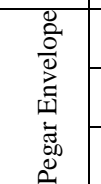 } & 5,08 & 3,32 & 5,10 & 8,48 & 6,14 & 3,72 & 4,38 & 5,77 & 5,20 & 4,45 & 3,93 & 5,58 & 3,90 & 4,93 & 4,43 & \multirow{3}{*}{4,84} \\
\hline & & & 3,95 & 5,42 & 5,07 & 3,78 & 4,54 & 4,41 & & & & & & & & & & \\
\hline & & & & & & & & & & & & & & & & & & \\
\hline \multirow{3}{*}{6} & \multirow{3}{*}{ 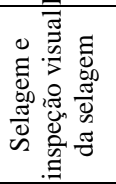 } & \multirow{3}{*}{ 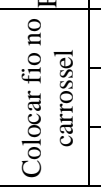 } & 7,44 & 7,68 & 7,49 & 7,35 & 8,09 & 8,65 & 7,23 & 7,38 & 7,62 & 8,53 & 8,18 & 8,28 & 8,22 & 8,16 & 8,67 & \multirow{3}{*}{8,01} \\
\hline & & & 8,42 & 9,13 & 7,59 & 8,01 & 8,91 & 7,24 & 8,36 & 7,62 & & & & & & & & \\
\hline & & & & & & & & & & & & & & & & & & \\
\hline & & & & & & & & & & & & & & & \multicolumn{3}{|c|}{ Tempo Médio } & 56,63 \\
\hline & & & & & & & & & & & & & & & \multicolumn{3}{|c|}{ Maior tempo } & 78,26 \\
\hline & & & & & & & & & & & & & & & \multicolumn{3}{|c|}{ Menor tempo } & 45,58 \\
\hline
\end{tabular}

Fonte: Autores (2020).

Nota-se que a atividade 1 leva mais tempo no processo, 20,9 segundos. Durante este processo a equipe percebeu que algumas atividades poderiam ser realizadas pela líder de produção, com um ato simples de abastecimento de materiais necessários para cada atividade, assim reduzindo parada de produção das colaboradoras a todo momento que precisasse de abastecer o suporte com agulhas e o suporte com os fios. Na atividade 2 e 3 notou-se que também poderia ser abastecida conforme fosse a necessidade de materiais, e também para auxiliar a fixação da espuma no rótulo interno, foi solicitado um suporte para colocar as espumas de uma maneira que fosse mais prática para realizar a fixação dela no rótulo durante o processo, o que reduziria o tempo no processo e facilitaria a execução da tarefa pelas operadoras. 

um estudo de caso em uma indústria de produtos médicos. Brazilian Journal of Production Engineering, 6(7), 68-89.

Figura 4. Aplicação do A3

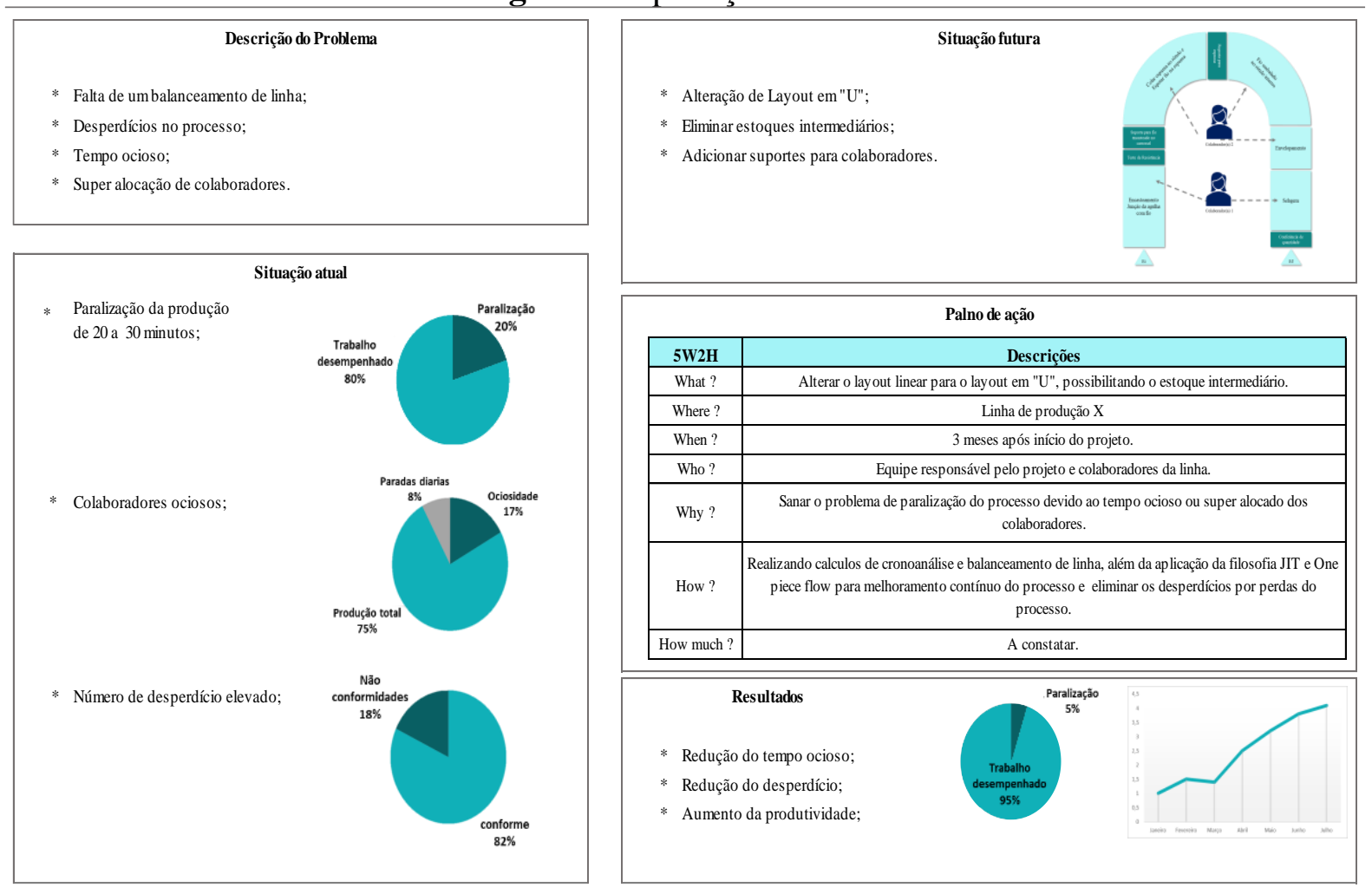

Fonte: Autores (2020).

Segundo o gestor da empresa a produção estava muito estagnada, fazia tempo que não havia melhora de produção, assim planejar um novo método de layout onde poderia tirar os desperdícios fazendo com que produzisse mais sem aumentar a produção, seria essencial. Para planejar as ações do projeto, assim como controlá-lo, foi realizada uma nova reunião com a equipe, similar ao brainstorming realizado anteriormente. Utilizou-se a ferramenta A3, conforme Saad (2013), Figura 4, para o projeto. A aplicação desta ferramenta, já utilizada pela empresa, auxiliou na compreensão do problema, buscando se tornar um catalisador para a transformação continuamente aprimorada.

No primeiro espaço do A3 foram apresentados os antecedentes do problema, contendo informações relevantes para conectar o problema ao contexto organizacional e histórico mais amplo. Nas condições atuais foram avaliadas as horas de paralização, a ociosidade das colaboradoras e a quantidade de peças desperdiçadas no processo, identificadas por meio da cronoanálise realizada.

Para a situação futura a equipe chegou ao consenso que a melhor maneira para solucionar este problema seria a alteração do layout celular em linha para um layout celular em formato "U", eliminando a presença de estoques intermediários, o que evitaria a paralização do processo por espera de recursos. Nesta etapa também foram avaliados o suporte para fios (carrossel) que necessitava de um imã menor, pois o objetivo é eliminar estoques intermediários e também o suporte para colocar a espuma, para poder facilitar na colagem.

A definição de mapeamento do fluxo de valor auxiliou na demonstração do fluxo de dados e o fluxo de materiais durante o processo de produção. Possibilita-se a identificação dos resíduos

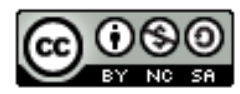



um estudo de caso em uma indústria de produtos médicos. Brazilian Journal of Production Engineering, 6(7), 68-89.

gerados. Plano de implementação, utilizando o 5W2H, de acordo com Danno, et al., (2019) apresentado no tópico 2.3.5, e pelo Quadro 3, apresenta as ações necessárias para realizar a condição de destino, quem executará cada ação e quando.

Quadro 3. Planejamento do Projeto - 5W2H

\begin{tabular}{|c|c|}
\hline 5W2H & Descrições \\
\hline What? & $\begin{array}{c}\text { Alterar o layout celular para o layout celular em formato de "U", impossibilitando o estoque } \\
\text { intermediário. }\end{array}$ \\
\hline Where? & Linha de produção X \\
\hline When? & 3 meses após início do projeto. \\
\hline Who? & Equipe responsável pelo projeto e colaboradores da linha. \\
\hline Why? & $\begin{array}{c}\text { Sanar o problema de paralização do processo devido ao tempo ocioso ou super alocado dos } \\
\text { colaboradores. }\end{array}$ \\
\hline How? & $\begin{array}{l}\text { Realizando cálculos de cronoanálise e balanceamento de linha, além da de testes por meio do } \\
\text { protótipo de papelão. Permitindo a alteração do Layout para formato em "U" em busca do } \\
\text { melhoramento contínuo do processo e eliminar os desperdícios por perdas do processo. }\end{array}$ \\
\hline How much? & A constatar. \\
\hline
\end{tabular}

Fonte: Autores (2020).

\subsubsection{TESTE PILOTO}

Para a implementação do projeto foi criada um protótipo em papelão, com a equipe envolvida no processo de melhoria, com o responsável do setor, os gestores do projeto e as colaboradoras das etapas da célula. No qual foram discutidas as principais questões de implementação. Este protótipo foi utilizado para definir as principais alterações a serem realizadas na planta real, no qual foram testados vários layouts em formato de "U", até a identificação do melhor arranjo possível. Evitando o gasto de tempo e monetário desnecessários na aplicação real para testes. A apresentação das imagens do modelo em papelão não foi permitida pela empresa.

\subsubsection{APLICAÇÃO DAS ATIVIDADES E ANÁLISE DOS DADOS}

Após a definição do layout celular em formato de "U" mais adequado para o processo buscando alcançar o nível mais baixo de estoque no processo, eliminação de desperdício, melhoria contínua da qualidade e incentivo à participação do trabalhador no planejamento e execução das operações. A alteração do layout foi planejada em conjunto com o setor de planejamento e controle da produção (PCP) e equipe de engenharia de processos da empresa, para identificar a melhor data para a execução. Após a aplicação do layout, foi realizado uma reunião com as colaboradoras da célula e um treinamento para explicação da nova forma de trabalho, já as colaboradas da linha participaram de todo processo, desde o começo na maquete de papelão fazendo todos os testes junto a equipe.

A reunião, ministrada pelo responsável do projeto, foi executada para esclarecer o funcionamento do novo layout para os líderes do setor. Após este entendimento os treinamentos das colaboradoras na célula em formato "U" foi ministrado também pelo responsável do projeto, em conjunto com os líderes do setor. Inicialmente foi apresentado de forma gráfica, Figura 5, para exibir uma visão inicial das perspectivas do funcionamento do projeto. Em seguida foram realizados treinamentos nos postos de trabalho, para sanar as dúvidas existentes.

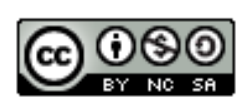




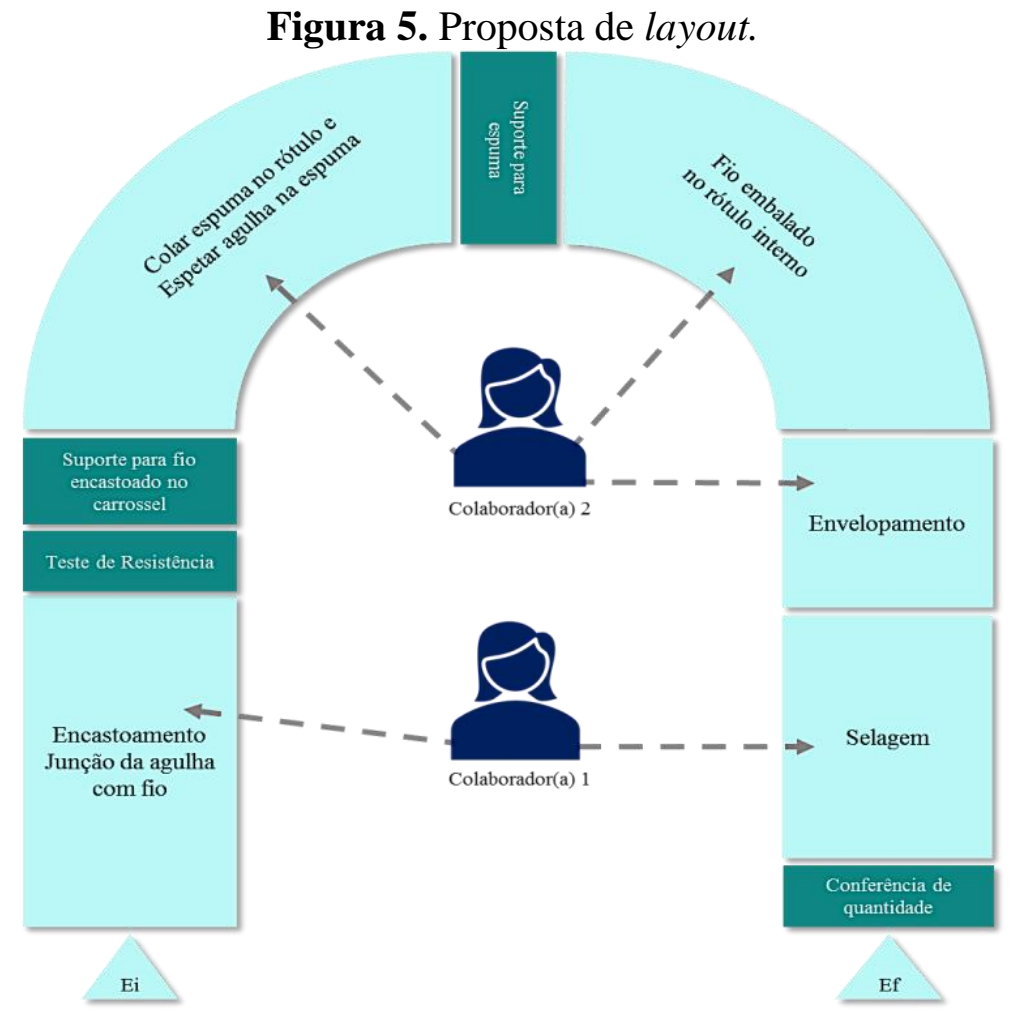

Fonte: Autores (2020).

O número de colaboradoras na célula em formato de "U" reduziu de 5 para 2 colaboradoras. Que inicialmente levou as colaboradoras apresentarem certa resistência a novidade, porém ao desenvolver do treinamento estas visualizaram o benefício que a alteração poderia trazer para elas. No dia seguinte, os dados foram coletados novamente, adicionados na Tabela Heijunka, e realizada uma nova cronoanálise. Esses resultados de medição são apresentados na próxima seção.

\subsubsection{RESULTADOS DA MELHORIA}

A nova cronometragem, disponível na Tabela 2, apresentou que as alterações do layout reduziram o tempo de processo em aproximadamente $17 \%$. Além do aumento de $10 \%$ na quantidade de envelopes.

Nota-se que a redução de tempo das colaboradoras 1 e 2 são respectivamente $5,78 \%$ e $10,99 \%$. Destacando a redução significativa de tempo nos processos envelopamento de 4,84 para $2,66,55 \%$ de redução, e no processo de selagem de 8,01 para 3,70 , redução de $54 \%$. O suporte para espuma auxiliou nessa redução de tempo, pois facilitou consideravelmente as atividades da colaboradora 2 .

Outro ponto a se destacar é que o menor tempo do processo apresenta uma redução de tempo em $13,05 \%$. Leva-se em consideração que o layout celular em formato "U" se encontra em fases de testes, e algumas alterações ainda podem ser avaliadas, para tentar reduzir ainda mais o tempo de processo. Por meio de análises nos maiores tempos, buscando reduzi-los cada vez mais.

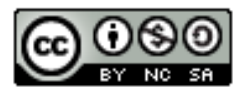



um estudo de caso em uma indústria de produtos médicos. Brazilian Journal of Production Engineering, 6(7), 68-89.

Em relação ao balanceamento de linha a Tabela 3 apresenta os resultados obtidos no processo após a alteração de layout em formato de "U". Percebe-se assim, que a produção esperada era de 14.400 peças semanais, e a produção real excedeu as expectativas com 17.920 peças, conforme dados da empresa. Um aumento de produtividade de 19,64\%.

O balanceamento de linha proporcionou também a redução da ociosidade das colaboradoras, devido ao fato de que a distribuição de atividades possibilitou um trabalho contínuo sem acúmulo de estoques intermediários e com menos colaboradoras por célula. Em uma análise geral, percebe-se na Tabela 4, os benefícios que a alteração de layout proporcionou para a empresa alvo deste estudo.

Relacionada a disponibilidade, as paradas não planejadas caíram significativamente, atingindo 99\% de disponibilidade, como apresenta a Figura 6. Já em relação ao desempenho, segundo o líder da área, houve algumas pequenas paradas no processo e o tempo de fadiga é consideravelmente baixo. A produção do dia analisado atingiu 102 peças a mais que o esperado. De forma geral a célula atingiu $92 \%$ do desempenho total.

Por fim as perdas relacionadas a qualidade foram apenas 12 peças, todas elas correspondentes a perdas no processo, e nenhum retrabalho, possível devido a alteração de verificação por produto e não pela ordem de produção. Sendo elas representadas pela Figura 7com índice de qualidade de $99 \%$.

Tabela 1. Cronometragem após as alterações de layout (em segundos).

\begin{tabular}{|c|c|c|c|c|c|c|c|c|c|c|c|c|c|c|c|}
\hline \# & 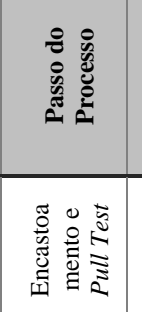 & \multirow{4}{*}{ 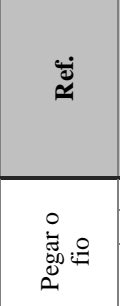 } & \multicolumn{10}{|c|}{ Tempo coletado } & \multirow{4}{*}{ 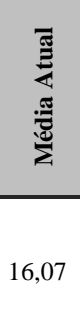 } & \multirow{4}{*}{ 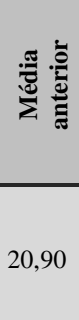 } & \multirow{7}{*}{ 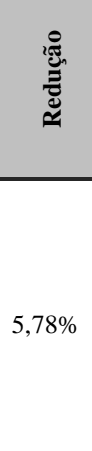 } \\
\hline & \multirow{3}{*}{ 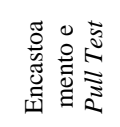 } & & 17,58 & 16,90 & 15,60 & 15,42 & 15,26 & 17,06 & 15,38 & 1,30 & 15,66 & 16,35 & & & \\
\hline \multirow{5}{*}{1} & & & 16,58 & 14,94 & 13,34 & 18,09 & 21,47 & 16,06 & 17,09 & 14,27 & 18,65 & 22,35 & & & \\
\hline & & & 18,96 & 16,18 & 15,04 & & & & & & & & & & \\
\hline & \multirow{3}{*}{ 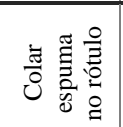 } & \multirow{3}{*}{ 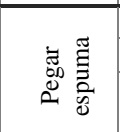 } & 3,52 & 2,85 & 2,54 & 3,15 & 3,05 & 2,98 & 2,76 & 2,34 & 3,21 & 2,43 & \multirow{3}{*}{2,88} & \multirow{3}{*}{3,83} & \\
\hline & & & 2,45 & 3,85 & 3,32 & 2,67 & 2,56 & 2,90 & 2,93 & 2,54 & 2,97 & 2,49 & & & \\
\hline & & & 2,87 & 2,90 & 2,98 & & & & & & & & & & \\
\hline \multirow{12}{*}{2} & \multirow{3}{*}{ 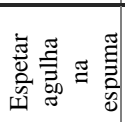 } & \multirow{3}{*}{ 总 } & 2,99 & 2,48 & 1,58 & 4,92 & 3,30 & 2,23 & 2,69 & 2,63 & 2,75 & 2,15 & \multirow{3}{*}{2,90} & \multirow{3}{*}{5,52} & \multirow{12}{*}{$10,99 \%$} \\
\hline & & & 2,39 & 2,21 & 5,63 & 2,72 & 2,17 & 2,28 & 2,69 & 1,81 & 4,00 & 4,09 & & & \\
\hline & & & 3,16 & 2,75 & 3,30 & & & & & & & & & & \\
\hline & \multirow{3}{*}{ 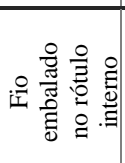 } & \multirow{3}{*}{ 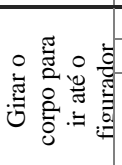 } & 10,88 & 11,34 & 11,58 & 11,22 & 11,65 & 11,82 & 12,13 & 11,49 & 11,27 & 10,61 & \multirow[b]{3}{*}{11,65} & \multirow[b]{3}{*}{13,53} & \\
\hline & & & 11,41 & 12,22 & 12,81 & 11,25 & 12,04 & 11,51 & 11,40 & 11,66 & 12,49 & 13,26 & & & \\
\hline & & & 11,21 & 11,67 & 11,17 & & & & & & & & & & \\
\hline & \multirow{3}{*}{ 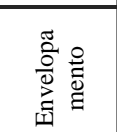 } & \multirow{3}{*}{ 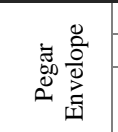 } & 3,46 & 1,85 & 2,23 & 2,87 & 3,50 & 3,15 & 1,89 & 2,34 & 2,76 & 2,63 & & & \\
\hline & & & 2,80 & 3,03 & 2,45 & 2,98 & 2,65 & 2,63 & 2,43 & 1,98 & 2,54 & 2,85 & 266 & 404 & \\
\hline & & & 2,56 & 3,10 & 2,67 & & & & & & & & & & \\
\hline & & & 3,96 & 2,79 & 2,58 & 3,86 & 5,34 & 3,71 & 3,08 & 2,66 & 4,87 & 3,29 & & & \\
\hline & Е జ & चี ஓ & 3,98 & 4,51 & 2,65 & 5,50 & 5,52 & 2,70 & 3,59 & 2,82 & 3,80 & 4,17 & & & \\
\hline & 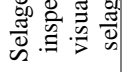 & 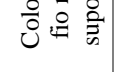 & 2,97 & 3,37 & 3,41 & & & & & & & & 3,70 & 8,01 & \\
\hline & & & & & & & & & & & npo M & & 39,86 & 56,63 & $-16,77 \%$ \\
\hline & & & & & & & & & Total & & ior ten & & 54,11 & 78,26 & $-24,15 \%$ \\
\hline & & & & & & & & & & & nor ten & & 32,53 & 45,58 & $-13,05 \%$ \\
\hline
\end{tabular}

Fonte: Autores (2020). 
- 85 -

Citação (APA): Amorin, L., Rodrigues, T. V., \& Silva Junior, J. F. da. (2020). Melhoria de eficiência produtiva de uma linha de produção: um estudo de caso em uma indústria de produtos médicos. Brazilian Journal of Production Engineering, 6(7), 68-89.

Tabela 2. Balanceamento de linha.

\begin{tabular}{|c|c|c|c|c|}
\hline Passos do Processo & $\begin{array}{l}\text { Tempo de } \\
\text { Ciclo (seg) }\end{array}$ & $\begin{array}{l}\text { Tempo de } \\
\text { Ciclo (seg) }\end{array}$ & $\begin{array}{c}\text { Unidades } \\
\text { /Hora }\end{array}$ & $\begin{array}{c}\text { Tempo } \\
\text { morto } \\
\text { (seg) }\end{array}$ \\
\hline Encastoamento e Pull Test & 16,07 & \multirow{2}{*}{18,95} & \multirow{2}{*}{162} & \multirow{2}{*}{0} \\
\hline Colocar o fio encastoado no suporte & 2,88 & & & \\
\hline Espetar agulha na espuma & 2,90 & \multirow{4}{*}{20,91} & \multirow{4}{*}{169} & \multirow{4}{*}{1,06} \\
\hline Fio embalado no rótulo interno & 11,65 & & & \\
\hline Envelopamento & 2,66 & & & \\
\hline Selagem e inspeção visual da selagem & 3,70 & & & \\
\hline
\end{tabular}

\begin{tabular}{|c|c|c|c|c|}
\hline Demanda semanal & 14.400 & $\begin{array}{l}\text { Tempo de ciclo } \\
\text { ideal }\end{array}$ & 21,25 & Seg \\
\hline número Cel. & 1 & $\begin{array}{l}\text { Tempo de ciclo } \\
\text { Esperado }\end{array}$ & 24,00 & Seg \\
\hline Turnos por dia & 1 & $\begin{array}{l}\text { Takt } \\
\text { Time }\end{array}$ & 30,83 & Seg \\
\hline Dias por semana & 5 & Produção Esperada & 360 & Und/hora \\
\hline \multirow[t]{4}{*}{ Seg. trabalhados } & 147.960 & Produção Diária & 3.584 & Und \\
\hline & & Produção Semanal & 17.920 & Und \\
\hline & & $\begin{array}{l}\text { Produtividade } \\
\text { (unidades/associado/horas) }\end{array}$ & 72,8 & Und/hora \\
\hline & & $\begin{array}{l}\text { Eficiência do } \\
\text { Balanceamento }\end{array}$ & $97,91 \%$ & \\
\hline
\end{tabular}

Fonte: Autores (2020).

Tabela 3. Cálculos da Cronoanálise após a melhoria.

\begin{tabular}{|c|c|c|c|}
\hline \multicolumn{4}{|c|}{ Disponibilidade } \\
\hline 1 & Tempo disponível por Turno & 10 & Hrs \\
\hline 2 & Tempo disponível total & 600 & Min \\
\hline 3 & Paradas Planejadas & 108 & Min \\
\hline 4 & Tempo Disponível Líquido & 492 & Min \\
\hline 5 & Paradas Não Planejadas & 7 & Min \\
\hline 6 & Tempo Produtivo & 485 & Min \\
\hline 7 & Disponibilidade & $99 \%$ & \\
\hline \multicolumn{4}{|c|}{ Desempenho } \\
\hline 8 & Tempo de Ciclo Ideal & 21,2 & Seg \\
\hline 9 & Quantidade máxima de peças & 1309 & Und \\
\hline 10 & Produção Esperada (Peças boas - Perdas) & 1207 & Und \\
\hline 11 & Desempenho & $92 \%$ & \\
\hline \multicolumn{4}{|c|}{ Qualidade } \\
\hline 12 & Total defeitos esperados & 12 & Und \\
\hline 13 & Perdas & $1 \%$ & \\
\hline 14 & Retrabalho & $0 \%$ & \\
\hline 15 & Qualidade & $99 \%$ & \\
\hline
\end{tabular}

Fonte: Autores (2020). 
Figura 6. Disponibilidade

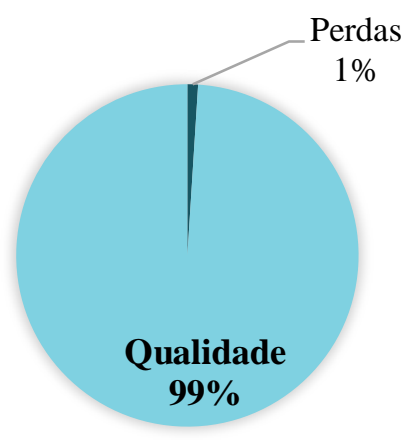

Figura 7. Qualidade

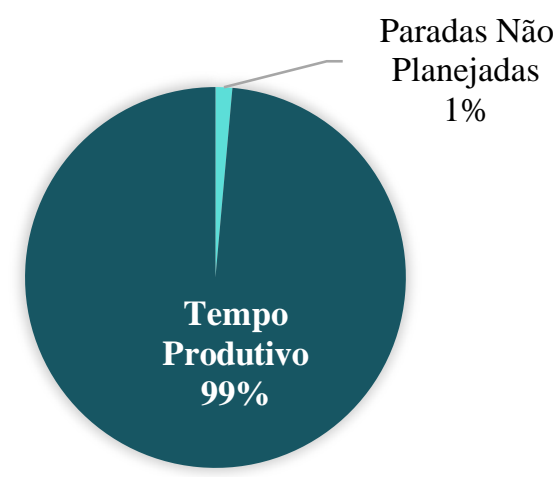

Fonte: Autores (2020).

Fonte: Autores (2020).

Em suma analisando as alterações realizadas neste trabalho baseadas nos desperdícios da produção, o estudo de cronoanálise e proporcionou a coleta de dados e a identificação de processos que possivelmente poderia atrasar o processo. $\mathrm{O}$ balanceamento de linha permitiu na identificação de um processo mais distribuído, eliminando os estoques intermediários, reduzindo os desperdícios por superprodução, além de reduzindo a movimentação das colaboradoras. Essa redução proporcionou uma melhoria na ergonomia das colaboradoras da célula, que passaram a realizar tarefas menos repetitivas e por estarem em constante movimento em curto espaço reclamaram menos de dores nas costas.

Por fim o balanceamento de linha apoiou a alteração do layout celular em "U", eliminando a ociosidade das colaboradoras e reduzindo o tempo de espera entre elas. Finalmente com as alterações observou-se que as atividades de retrabalho foram eliminadas, elevando os índices de qualidade. Vale ressaltar também que a alteração de layout apresentou uma melhoria do espaço físico, reduzindo cerca de $25 \%$ no espaço de cada célula em "U", comprovando que alterações simples sem a necessidade de gastos excessivos podem melhorar consideravelmente uma organização.

\section{CONSIDERAÇÕES FINAIS}

Este trabalho teve como objetivo adequar o layout do processo produtivo de uma indústria de produtos médicos para melhorar a eficiência produtiva, garantindo o aumento da qualidade e produção pelo índice de produtividade e redução de desperdícios. Para atingir tal objetivo foram avaliar os tempos de produção, por meio da cronoanálise e Heijunka, conforme objetivo (a), para assim compreender o estado atual da linha de montagem de fabricação, por meio de um Brainstorming, cumprindo o propósito (b). As reuniões possibilitaram o reconhecimento da parte principal do desperdício, problema e chances entre o processo, por meio da ferramenta A3, para propor um layout adequado, atendendo o objetivo (c). Por fim, a alteração do layout reduziu os desperdícios de movimentação e atividades que não agregam valor no processo produtivo (d), que foi possível por meio do balanceamento de linha no layout celular em "U”, como proposto em (e). 

um estudo de caso em uma indústria de produtos médicos. Brazilian Journal of Production Engineering, 6(7), 68-89.

Como principais resultados obtidos com estas alterações, destaca-se a redução de tempo do processo em aproximadamente $17 \%$, além da melhoria de alocação de recursos que aumentou em $10 \%$ a produção de envelopes por colaboradora. Pontua-se também o aumento de produtividade em aproximadamente $20 \%$. O balanceamento de linha proporcionou também a redução da ociosidade das colaboradoras, devido a distribuição de atividades de trabalho, sem acumulo de estoques intermediários e com menos colaboradoras por célula.

Além dos objetivos esperados, as ações realizadas neste trabalho trouxeram outros benefícios para a empresa, como a disponibilidade de produção e redução de paradas não planejadas que chegaram a 99\%, e desempenho de 92\%. E também alguns desperdícios da produção como: retrabalho; estoque; movimentação e espera, que foram melhorados significativamente. Além de melhorar o espaço de chão de fábrica. Respondendo assim a questão desta pesquisa, melhorando a eficiência produtiva, por meio de uma adequação de layout, e garantindo o aumento da produção.

Durante a aplicação das ferramentas mencionadas no decorrer do trabalho, foram enfrentadas algumas implicações, principalmente relacionada a aceitação das colaboradoras. Porém, com o desenrolar do projeto esta implicação foi eliminada pela percepção dos possíveis benefícios da alteração. Para trabalhos futuros cabe reavaliar o balanceamento de linha para aproximar ainda mais a redução de tempo entre as colaboradoras, pois pretende-se aplicar em outras famílias de produtos também. Além das demais atividades que reduziram pouco tempo se comparados com os processos de fio embalado no rótulo interno e o processo de selagem.

\section{Referências}

Albertin, M. R., \& Pontes, H. L. J. (2016). Gestão de processos e técnicas de produção enxuta. Curitiba: Editora Intersaberes.

Amolaro, C. L. (2019). Aplicação da metodologia SMED num processo de estampagem. Tese (Doutorado em Engenharia de Produção). Instituto Politécnico de Bragança. Bragança.

Antunes, J. (2009). Sistemas de produção: conceitos e práticas para projetos e gestão da produção enxuta. [s.1.] São Paulo, Bookman Editora.

Bruno. (2015). 10 coisas sobre competitividade que você ainda não sabe. Disponível em: <http://www.institutophd.com.br/blog/10-coisas-sobre-competitividade-que-voce-ainda-naosabe/> Acesso em: 10 de janeiro de 2020.

Chiarini, A., Baccarani, C., \& Mascherpa, V. (2018). Lean production, Toyota Production System and Kaizen philosophy. The TQM Journal, v. 1.

Colet. (2019). Layout industrial: análise para maior eficiência e produtividade. Disponível em: https://coletsistemas.com.br/layout-industrial-analise-para-maior-eficiencia-eprodutividade/. Acesso em: 12 de fevereiro de 2020.

Curi, P. C. (s/d). Tudo sobre produtividade e como ser mais produtivo no trabalho. Disponível em: https://rockcontent.com/blog/produtividade/. Acesso: 22 de janeiro de 2020.

D’agostini, M., Sartor, R. M., Tisott, P. B., Tondolo, V. A. G., \& Camargo, M. E. (2014). Escolha do Arranjo Físico de Produção: O Caso da Metalices Indústria Metalmecânica. Revista Alcance, 21(2), 369-394. 

um estudo de caso em uma indústria de produtos médicos. Brazilian Journal of Production Engineering, 6(7), 68-89.

Danno, C. H., Lemes, R. B., De Oliveira Guinossi, L. G. (2019). Ações para diminuição do indicador absenteísmo em unidades de internação, um relato de experiência. Revista Ciência \& Saberes-Facema, 4(2), 1128-1133.

Dataviva, (2017). Fabricação de Instrumentos e Materiais para Uso Médico em São Sebastião do Paraíso. Disponível em: http://dataviva.info/pt/location/4mg070812. Acesso: 15/05/2020

Dugosh, K. L., Paulus, P. B., Roland, E. J., \& Yang, H. C. (2000). Cognitive stimulation in brainstorming. Journal of personality and social psychology, 79(5), 722.

Fogliatto, F. S. R. (2009). Manutenção Industrial. Rio de Janeiro. Elsevier Editora.

Garau, C., \& Pavan, V. M. (2018). Evaluating urban quality: indicators and assessment tools for smart sustainable cities. Sustainability, 10(3), p. 575.

Gemba Produzzi. Você sabe o que é lean? (2018). Disponível em: https://produzzi.com/o-quee-lean/. Acesso em: 07/05/2020

Gil, A. C. (2008). Métodos e técnicas de pesquisa social. 6. ed. São Paulo: Editora Atlas SA.

Ibc Coaching, (2018). Como entender e aplicar o conceito de eficiência, eficácia e efetividade na minha empresa. Disponível em: https://www.ibccoaching.com.br/portal/ como-entender-eaplicar-o-conceito-de-eficiencia-eficacia-e-efetividade-na-minha-empresa/. Acesso em: 18 de janeiro de 2020.

Kikolski, M., \& Ko, C. (2018). Facility layout design-review of current research directions. Engineering Management in Production and Services, 10(3),70-79.

Lean Enterprise Institute, I. (2019). Heijunka. Disponível em: https://www.lean.org/lexicon/heijunka. Acesso em: 17 de abril de 2020

Liu, C., Su, K., \& Uang, S. (2019). The effects of layout types and spatial information display types on presence and spatial identification for the elderly in the $3 \mathrm{D}$ virtual art gallery. Journal of Ambient Intelligence and Humanized Computing, 10(9), 3439-3451.

Marconi, M. dE A., \& Lakatos, E. M. (2003). Fundamentos de metodologia científica. São Paulo: Atlas.

Martins, P. G., \& Laugeni, F. P. (2005). Administração da produção. São Paulo: Saraiva.

Miguel, P. A. C. (2007). Estudo de caso na engenharia de produção: estruturação e recomendações para sua condução. Production, 17(1), 216-229.

Miranda, D. (S/n). Os conceitos de "Tempo" na cronoanálise. Artigonal diretório de artigos gratuitos. Disponível em: artigos. com/artigos/engenharia/producao/osconceitosde-\% 93tempo, 2009.

Moreira, D. A. (2008). Produção e Operações. São Paulo: Pioneira.

Ohno, T. (1997). O sistema Toyota de produção além da produção. São Paulo, Bookman.

Oliveira, C. L. P. A. (2009). Análise e controle da produção em empresa têxtil, através da cronoanálise. 46 f. Trabalho de conclusão de curso (Bacharel em Engenharia de Produção) Centro Universitário de Formiga - UNIFOR-MG, Formiga.

Oliveira, N. P., et al. (2019). Risk Management: The Differences Between North American and European Markets/Gerenciamento de riscos: as diferenças entre os mercados norteamericano e europeu. Brazilian Journal of Business, 1(4), 1592-1604.

Osborne, A. F. (1957). Applied imagination. New York, NY: Scribner.

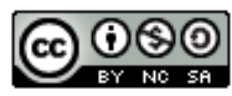



um estudo de caso em uma indústria de produtos médicos. Brazilian Journal of Production Engineering, 6(7), 68-89.

Peinado, J., Graeml, A. R. (2007). Administração da produção. Operações industriais e de serviços. Curitiba: Unicenp.

Pinto, J. P. (2009). Pensamento Lean: A filosofia das organizações vencedoras. Lisboa: Lidel. Radhakrishnan, N. S., Singh, H, \& Southwick, F. S. (2019). Teaching novice clinicians how to reduce diagnostic waste and errors by applying the Toyota Production System. Diagnosis, 6(2), 179-185.

Rodrigues, T. V., De Jesus, R. G., \& Oliveira, N. P. (2019). A Importância Do Gerenciamento De Projetos Para Pequenas E Médias Empresas. Gestão e Desenvolvimento em Revista, 5(1), 4-12.

Rodrigues, T. V., Queiroz, L. M. S., Sanjulião, L. R. K. A. F., \& Santos Filho, V. H. (2020). Sustainability: floor waterproofing feasibility study and rainwater reuse in a textile industry: sustentabilidade: estudo de viabilidade de impermeabilização de pisos e reutilização de água de chuva em uma indústria têxtil. Brazilian Journal of Production Engineering, 122-134.

Rodrigues, T. V., Queiroz, L. M. S., Junior, J. D. S. F., Sanjulião, L. R. K. A. F., \& Oliveira, N. P. (2020b). Simulation layout proposal in a brazilian textile industry: proposta de layout de simulação em uma indústria têxtil brasileira. Brazilian Journal of Production Engineering, $10-23$.

Saad, N. M., Al-Ashaab, A., Shehab, E., \& Maksimovic, M. (2013). A3 thinking approach to support problem solving in lean product and process development. In: Concurrent Engineering Approaches for Sustainable Product Development in a Multi-Disciplinary Environment. Springer, London. 871-882.

Santos, A. L. V., \& Reis, R. R. (2019). A Importância do layout para as empresas. Revista Interface Technologic, 16(2), 157-168.

Santos, V. M. (2019). Ferramentas para solução de problemas. Disponível em: https://www.fm2s.com.br/ferramentas-para-solucao-de-problemas/. Acesso em: 20 de março de 2020.

Seixas, H. L. S. (2014). Análise de fluxo e redefinição do layout da área produtiva. 145 f. Dissertação (Mestrado em Engenharia de Produção) Universidade do Porto, Porto, Portugal.

Sharma, A. M., \& Patricia, E. (2003). A máquina perfeita. São Paulo: Atlas.

Shingo, S. (1996). Toyota Production System: from the point of view of Production Engineering. Porto Alegre: Publisher Bookman.

Slack, N., Chambers, S., \& Johnston, R. (2009). Administração da produção. São Paulo: Atlas.

Sobek II, D. K., \& Jimmerson, C. (2004). A3 reports: tool for process improvement. In: IIE Annual Conference. Proceedings. Institute of Industrial and Systems Engineers (IISE). p. 1.

Sotsek, N. C., \& Bonduelle, G. M. (2017). Melhorias em uma empresa de embalagens de madeira através da utilização da cronoanálise e rearranjo de layout. Floresta, 46(4), 519-530.

Toledo Jr, I. F. B., \& Kuratomi, S. (1977). Cronoanálise base da racionalização, da produtividade da redução de custos. 3. ed. São Paulo: Itysho.

Turrioni, J. B., \& Mello, C. H. P. (2012). Metodologia de pesquisa em engenharia de produção: estratégias, métodos e técnicas para condução de pesquisas quantitativas e qualitativas. Apostila do curso de Especialização em Qualidade e Produtividade. Universidade Federal de Itajubá, Itajubá, MG. 